\title{
The Evaluation of Mandibular First Permanent Molars to Determine the Incidence of Three Roots and Four Canals in Aljouf Region of Saudi Arabia
}

\author{
Azhar lqbal \\ Assistant professor, Department of Operative Dentistry, College of Dentistry, \\ AlJouf University, Kingdom of Saudi Arabia.
}

\begin{abstract}
Introduction: The prime objective of the endodontic treatment is the restoration of function and esthetics of the involved tooth. The thorough debridement and the three dimensional root canal filling of the root canal system is the sole objective of the endodontic therapy. Therefore it is of utmost importance that the dentist must have a thorough knowledge of root canal morphology of the tooth being treated. This will enable the treating dentists to locate all root canals and to remove successfully all pulp tissue and debris during the treatment.

Aims and Objectives: The aim of this study is to evaluate the mandibular first permanent mandibular molars for the incidence of three roots and four canals in the population of Saudi Arabia of Aljouf region.

Materials and Methods: A total of 100 patients, requiring root canal treatment for first mandibular molar were included in this study. The patients from both genders, with age range 20-50 years, having adequate mouth opening, and were cooperative were included in this study. The preoperative radiographs, working length radiographs and post obturation radiographs, were taken by buccal Buccal Object,s Rule technique (SLOB Rule). These $x$-rays were mounted on $x$-ray mounts, were projected on $x$-ray viewer and were evaluated by using magnifying glass. The number of roots and root canals were recorded. Roots with multiple canal systems were categorized according to whether the canals will exit the root by a common apical foramen or by separate apical foramen. The fourth canal was further categorized as separate from distal canal or joined by isthmus. The collected data was analyzed by using computer software SPSS version 21.
\end{abstract}

Results: In the present study, out of a total of 100 samples, 88 were males, 12 were females, 48 belonged to 20 to 30 years, 29 were in 30 to 40 years of age group and 23 were in 40 to

\section{INTRODUCTION}

The main goal of endodontics is to restore the function and esthetic of the involved tooth. In root canal treatment, complete debridement and obturation of the entire root canal system is considered to be the main objective of the therapy. ${ }^{1}$ It is therefore of utmost importance that the dentist has a thorough knowledge of root canal morphology of the tooth being treated. ${ }^{2}$

The earliest permanent posterior tooth to erupt, the mandibular first molar seems to be the tooth that most often requires root
50 years of age groups. Further, a maximum of 44 were belonging to Saudi nationals followed by 17 each were Indians and Pakistanis, 12 were Egyptians and 10 were Jordanian. Six teeth out of a total of 100 samples were found to be threerooted. Regarding the occurrence of the fourth canal, this study revealed that $63.0 \%$ had four root canals. No statistical difference between gender and nationalities was observed except the association between age groups and incidence of third root and fourth canal was found to be statistically not significant.

Conclusion: The observations of the present study are very significant in assisting the dental practitioners to provide adequate knowledge about the root canal morphology of the majority of population residing in Kingdom of Saudi Arabia and about the possible morphological variations.

Keywords: Mandibular First Molar, Third Root, Root Canal Morphology, Fourth Canal.

\section{${ }^{*}$ Correspondence to:}

\section{Dr. Azhar lqbal,}

Assistant professor,

Department of Operative Dentistry, College of Dentistry, AlJouf University, Kingdom of Saudi Arabia.

\section{Article History:}

Received: 25-08-2016, Revised: 16-09-2016, Accepted: 28-09-2016

\begin{tabular}{|l|c|}
\hline \multicolumn{2}{|c|}{ Access this article online } \\
\hline $\begin{array}{l}\text { Website: } \\
\text { www.ijmrp.com }\end{array}$ & Quick Response code \\
\hline DOI: & \\
10.21276/ijmrp.2016.2.5.047 & \\
\hline
\end{tabular}


Several methodologies have been used to study the root canal system configuration of the first mandibular molar. They include plastic resin injection, endodontic access and radiographs with files placed into the canals, retrospective radiographic evaluation, clearing of samples with or without injection of ink, scanning electron microscopy (SEM) evaluation, computed tomography (CT), spiral computed tomography (SCT), micro- computed tomography $(\mathrm{mCT})$, and cone-beam computed tomography (CBCT). Although many modernized methodologies have been introduced for studying root canal system, and also the use of radiographic techniques might appear to have certain disadvantages, this method is still the most reliable and popular method in clinical sitting. ${ }^{5}$

Apart from this the major variant in mandibular first molars is the presence of a supernumerary root that can be found distolingually and has a curve at the apex. This macrostructure, first mentioned by Carabelli, is called radix entomolaris, which in general is smaller than distobuccal and mesial roots and can be separate from or partially fused with other roots. The morphology and buccolingual width of the mesial root allow for intercanal communications and isthmuses. ${ }^{6}$ Currently, the isthmus (anastomosis) is defined as a pulpal passageway connecting two or more canals in the same root. ${ }^{7}$

Although the incidence in different countries of four root canals and third root in the mandibular first molar has been reported in most endodontic textbooks, there is a need to know the incidence among the population of Saudi Arabia. Therefore, the purpose of this investigation was to study the prevalence of four root canals and third root in the permanent mandibular first molars in the population of Saudi Arabia of Aljouf region.

\section{MATERIAL AND METHODS}

A clinical, radiographical, prospective study was carried out in the Department of Restorative Dentistry, College of Dentistry, Aljouf University from June 2015 to Dec 2015. A total of 100 patients who were seeking root canal therapy for the mandibular first permanent molar (Both males and Females) were included in the present study.

These patients were treated by the Intern Dentists, Teaching Assistants and Consultant Endodontists. To carry out this study a written approval was taken from the Institutional Esthetical Committee. The informed consent was taken from the participants of this study. After the informed consent, the data was collected on specially designed proforma. The patient both male and female having age range 20 to 50 years, having adequate mouth opening, and cooperative were included in this study. The patients above 50 years, having medical problems, limited opening of mouth, macroglossia, unrestorable teeth, teeth with severe root resorption, dilacerated roots, pregnant women and malformed teeth were not included in the study. The fourth canal incidence was diagnosed by using the periapical radiographs taken by buccal object rule during the pulpectomy, working length determination, preparation and post obturation. The periapical radiographic film taken during working length determination and obturation at different angulations were mounted, projected and then evaluated. The distal canal if present was further categorized as separated from main distal canal, joined by isthmus, short or full length and size of preparation of the fourth canal $(25,30,40$ file size). A total of 135 root canal treated mandibular first molars were studied. The teeth were randomly selected. Seventy three were from male and sixty two were from female patients. These patients were treated under strict supervision of an endodontist. After access cavity preparation and removal of coronal pulp of each tooth the floor morphology and the canal orifice identification were properly evaluated by an endodontist. The $\mathrm{x}$ rays were taken at different angles during working length determination and after obturating the root canals of each tooth were mounted and evaluated. The radiographs were examined by an expert having 10 years' experience. The clinical records were analyzed and the findings were then tabulated and recorded on a special form for each individual patient. Roots with multiple canal systems were categorized according to whether the canals exited the root by a common apical foramen or by separate apical foramina. All the examined teeth were free of root resorption, had no canal calcification, open apices, broken instrument and no previous root canal therapy. The collected data was analyzed with computer software SPSS version 21 by using Chi Square test.

Table 1: Distribution of samples by gender, age groups and nationality

\begin{tabular}{lcc}
\hline Factors & N & $\%$ \\
\hline Gender & & \\
Male & 88 & 88.00 \\
Female & 12 & 12.00 \\
Age groups & & \\
Group 1 ( 20 to 30) & 48 & 48.00 \\
Group 2 ( 30 to 40 ) & 29 & 29.00 \\
Group 3 ( 40 to 50) & 23 & 23.00 \\
Nationality & & \\
Saudi & 44 & 44.00 \\
Indian & 17 & 17.00 \\
Pakistani & 17 & 17.00 \\
Egyptian & 12 & 12.00 \\
Jordanian & 10 & 10.00 \\
Total & 100 & 100.00 \\
\hline
\end{tabular}

\section{RESULTS}

In the present study, out of a total of 100 samples, 88 were males, 12 were females, 48 belonged to 20 to 30 years, 29 were in 30 to 40 years of age group and 23 were in 40 to 50 years of age groups. Further, a maximum of 44 were belonging to Saudi nationals followed by 17 each were Indians and Pakistanis, 12 were Egyptians and 10 were Jordanian (Table 1).

From the results of the table 2 , it can be seen that,

- The incidence of third root in males was $6.82 \%$ and none of the female had incidence of third root. The difference was not found to be statistically significant (Yates corrected chisquare $=0.0813, p=0.7756$ ).

- A maximum of $10.34 \%$ of respondents belonging to 30 to 40 years of age group had incidence of third root as compared to $4.17 \%$ and $4.35 \%$ respectively in respondents belonging to 20 to 30 years and 40 to 50 years of age group. The association between age groups and incidence of third root was found to be statistically not significant (chisquare $=1.3680, p=0.5046$ ). 
- A maximum of $11.76 \%$ of Pakistanis and $10.00 \%$ of Jordanian had incidence of third root followed by $6.82 \%$ of Saudis had incidence of third root. But surprisingly, none of the Indians and Egyptians were having third root. The difference was not found to be statistically significant (chisquare $=3.1886, p=0.5268$ ).

From the results of the table 3 , it can be seen that,

- Incidence of fourth canal was observed in males was $61.36 \%$ as compared to $75.00 \%$ of female having incidence of fourth canal. The difference was not found to be statistically significant (chi-square $=0.3590, p=0.5491$ ).

- A maximum of $72.92 \%$ of respondents belonging to 20 to 30 yrs of age group had incidence of fourth canal as compared to $51.72 \%$ and $56.52 \%$ respectively in respondents belonging to 30 to 40 years and 40 to 50 years of age group. The association between age groups and incidence of fourth canal was found to be statistically not significant (chisquare $=4.0209, p=0.1339$ ).

- A maximum of $80.00 \%$ of Jordanians, $68.18 \%$ of Saudis and $64.71 \%$ of Indian had incidence of fourth canal followed by
47.06 of Pakistanis and $50.00 \%$ Egyptian having incidence of fourth canal. The difference was not found to be statistically significant (chi-square=4.4912, $p=0.3436$ ).

Table 4 reveals that the incidence of third root in permanent mandibular first molar in left side was $66.67 \%$ and in right side is $33.33 \%$. The difference was not found to be statistically significant (Yates correction chi-square $=0.3334, p=0.5642$ ).

From the observations of table 5 , it can be seen that the incidence of fourth canal on left sidewas $49.21 \%$ and on right side was $50.79 \%$. The difference was not found to be statistically significant (Chi-square $=0.0321, p=0.8593$ ).

From the results of the table 6 , it can be seen that, the incidence of third root in preoperative periapical radiograph was $100 \%$ and also $100 \%$ were located during determination of working length The difference was not found to be statistically significant.

From the results of the table 7, it can be seen that, the incidence of fourth canal in preoperative periapical radiograph was 19.05\% and those located during working length determination was $98.41 \%$. The difference was found to be statistically significant (Yates correction chi-square $=78.6192, p=0.0001$ ).

Table 2: Incidence of third root according to gender, age groups and nationality

\begin{tabular}{lccccccc}
\hline Factors & No & $\%$ & Yes & $\%$ & Total & Chi-square & P-value \\
\hline Sex & 82 & 93.18 & 6 & 6.82 & 88 & & \\
Male & 12 & 100.00 & 0 & 0.00 & 12 & 0.0813 & 0.7756 \\
Female & & & & & & & \\
Age groups & 46 & 95.83 & 2 & 4.17 & 48 & & \\
Group 1 ( 20 to 30) & 26 & 89.66 & 3 & 10.34 & 29 & 1.3680 & 0.5046 \\
Group 2 ( 30 to 40) & 22 & 95.65 & 1 & 4.35 & 23 & & \\
Group 3 ( 40 to 50) & & & & & & & \\
Nationality & 41 & 93.18 & 3 & 6.82 & 44 & & \\
Saudi & 17 & 100.00 & 0 & 0.00 & 17 & & \\
Indian & 15 & 88.24 & 2 & 11.76 & 17 & & \\
Pakistani & 12 & 100.00 & 0 & 0.00 & 12 & 3.1886 & \\
Egyptian & 9 & 90.00 & 1 & 10.00 & 10 & & \\
Jordanian & 94 & 94.00 & 6 & 6.00 & 100 & & \\
Total & 94 & & & & &
\end{tabular}

Table 3: Incidence of fourth canal according to gender, age groups and nationality

\begin{tabular}{lccccccc}
\hline Factors & No & $\%$ & Yes & $\%$ & Total & Chi-square & P-value \\
\hline Sex & 34 & 38.64 & 54 & 61.36 & 88 & & \\
Male & 3 & 25.00 & 9 & 75.00 & 12 & 0.3590 & 0.5491 \\
Female & & & & & & & \\
Age groups & 13 & 27.08 & 35 & 72.92 & 48 & & \\
Group 1 ( 20 to 30) & 14 & 48.28 & 15 & 51.72 & 29 & 4.0209 & 0.1339 \\
Group 2 ( 30 to 40) & 10 & 43.48 & 13 & 56.52 & 23 & & \\
Group 3 ( 40 to 50) & & & & & & \\
Nationality & 14 & 31.82 & 30 & 68.18 & 44 & & \\
Saudi & 6 & 35.29 & 11 & 64.71 & 17 & & \\
Indian & 9 & 52.94 & 8 & 47.06 & 17 & 4.4912 & 0.3436 \\
Pakistani & 6 & 50.00 & 6 & 50.00 & 12 & & \\
Egyptian & 2 & 20.00 & 8 & 80.00 & 10 & & \\
Jordanian & 37 & 37.00 & 63 & 63.00 & 100 & & \\
Total & & & &
\end{tabular}


Azhar Iqbal. Evaluation of Mandibular First Permanent Molars to Determine the Incidence of 3 Roots \& 4 Canals

Table 4: Incidence of third root in permanent mandibular first molar according side

\begin{tabular}{lcccccc}
\hline Third root & $\begin{array}{c}\text { Mandibular Left } \\
\text { First Molar }\end{array}$ & $\%$ & $\begin{array}{c}\text { Mandibular Right } \\
\text { First Molar }\end{array}$ & $\%$ & Chi-square & p-value \\
\hline No & 2 & 33.33 & 4 & 66.67 & $0.3334 \#$ & 0.5642 \\
Yes & 4 & 66.67 & 2 & 33.33 & & \\
Total & 6 & 6.00 & 6 & 6.00 & & \\
\hline
\end{tabular}

\#applied chi-square with yates correction

Table 5: Incidence of fourth canal in permanent mandibular first molar according side

\begin{tabular}{lcccccc}
\hline Fourth canal & $\begin{array}{c}\text { Mandibular Left } \\
\text { First Molar }\end{array}$ & $\%$ & $\begin{array}{c}\text { Mandibular Right } \\
\text { First Molar }\end{array}$ & $\%$ & Chi-square & $p$-value \\
\hline No & 32 & 50.79 & 31 & 49.21 & & \\
Yes & 31 & 49.21 & 32 & 50.79 & 0.0321 & 0.8593 \\
Total & 63 & 63.00 & 63 & 63.00 & & \\
\hline
\end{tabular}

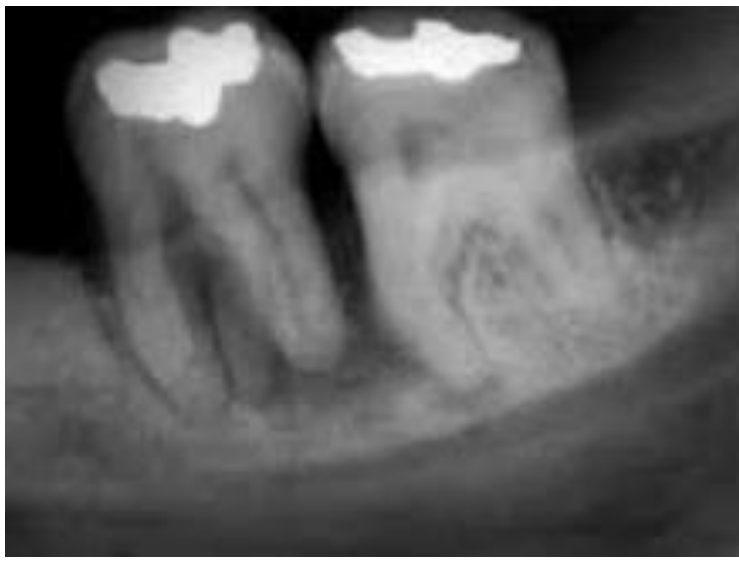

Fig 1: Mandibular left first molar having third root

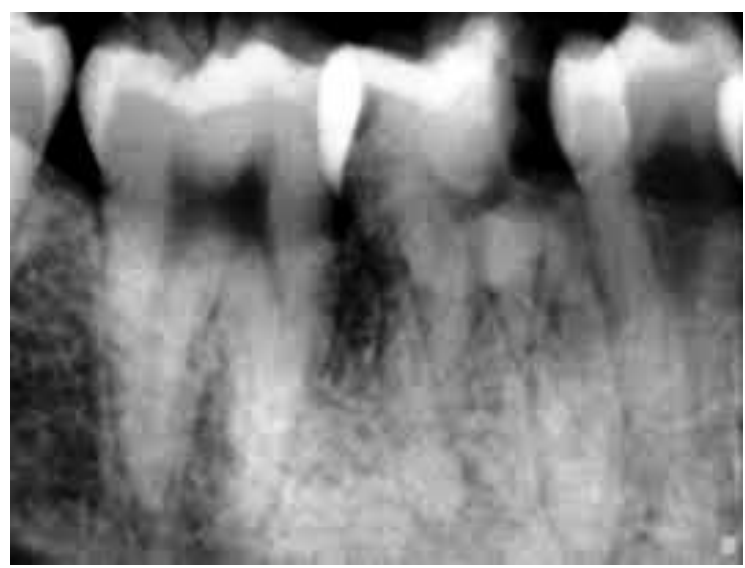

Fig 3: Mandibular left first with third root

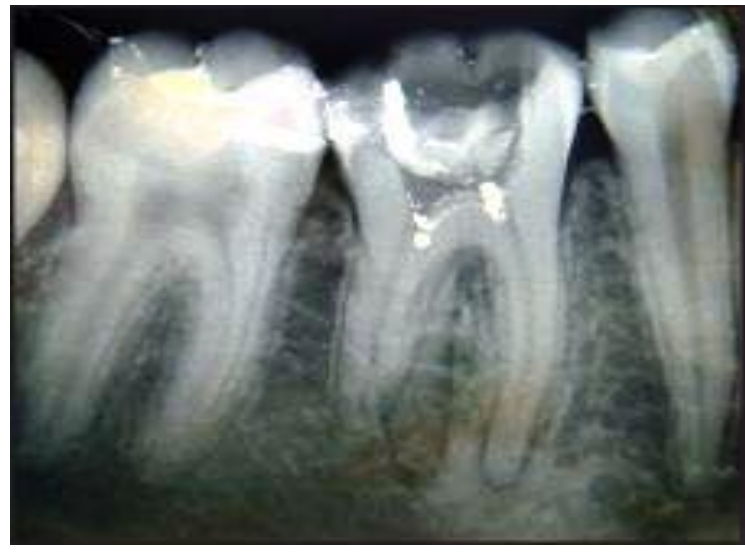

Fig 5: Mandibular right first molar having third root

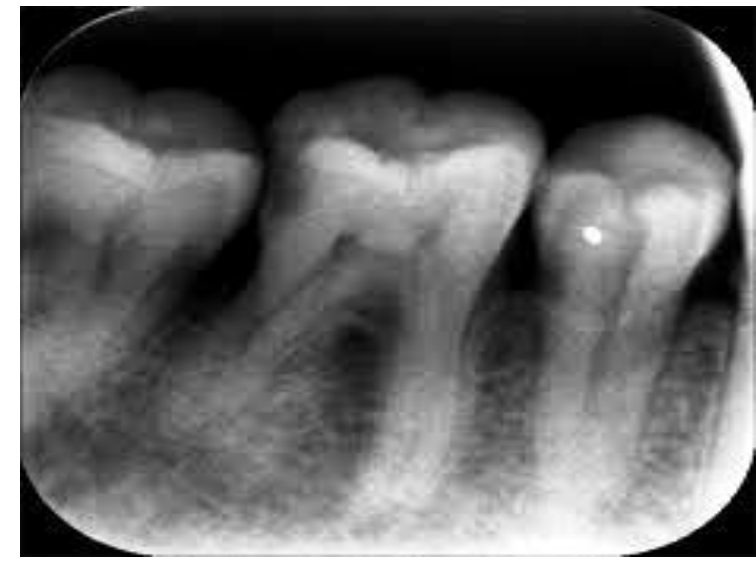

Fig 2: Mandibular right first molar having third root

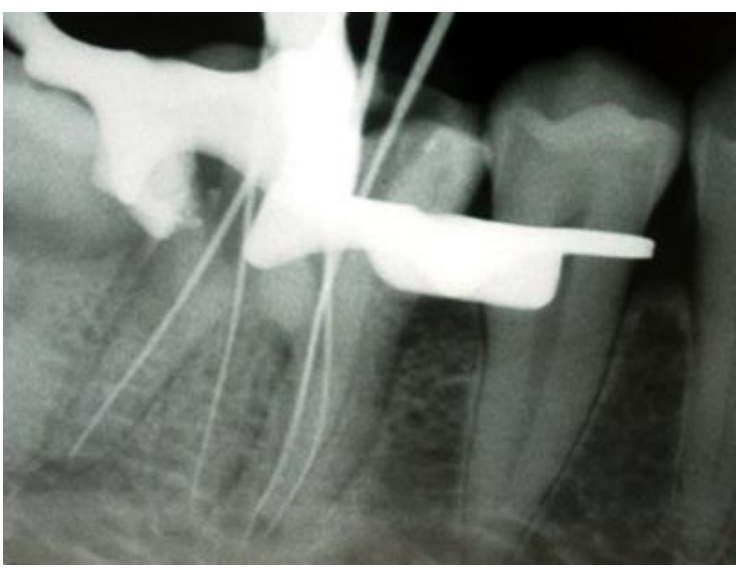

Fig 4: Mandibular right first molar having third root and fourth canal

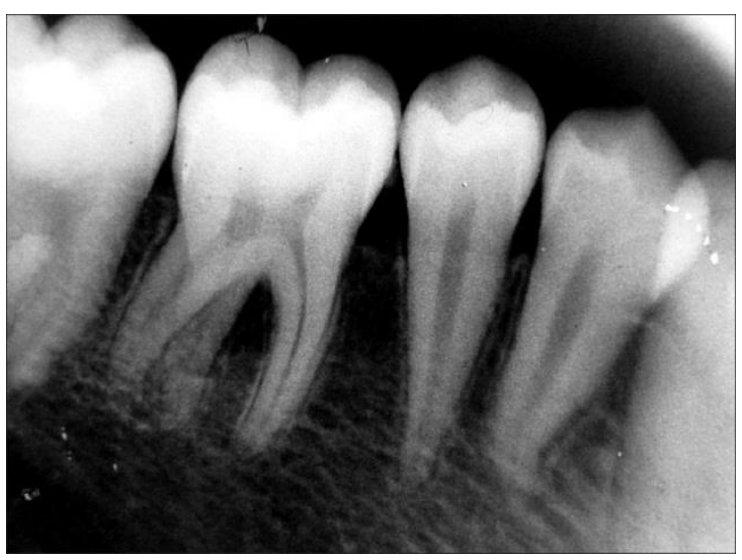

Fig 6: Mandibular right first molar with third root 
Azhar Iqbal. Evaluation of Mandibular First Permanent Molars to Determine the Incidence of 3 Roots \& 4 Canals

Table 6: Location of third root in permanent mandibular on preoperative periapical radiograph and located during working length determination

\begin{tabular}{lccccc}
\hline Third root & $\begin{array}{c}\text { Preoperative Periapical } \\
\text { Radiograph }\end{array}$ & $\%$ & $\begin{array}{c}\text { Located during working length } \\
\text { determination }\end{array}$ & $\%$ & -value \\
\hline No & 0 & 0.00 & 0 & 0.00 & 1.0000 \\
Yes & 6 & 100.00 & 6 & 6.00 & \\
Total & 6 & 6.00 & 6 & 6.00 & \\
\hline
\end{tabular}

Table 7: Location of fourth canal in permanent mandibular on preoperative periapical radiograph and located during working length determination

\begin{tabular}{lcccccc}
\hline $\begin{array}{l}\text { Fourth } \\
\text { canal }\end{array}$ & $\begin{array}{l}\text { Preoperative } \\
\text { Periapical } \\
\text { Radiograph }\end{array}$ & $\%$ & $\begin{array}{l}\text { Located during } \\
\text { working length } \\
\text { determination }\end{array}$ & $\%$ & Chi-square & p-value \\
\hline No & 51 & 80.95 & 1 & 1.59 & $0.0001^{*}$ \\
Yes & 12 & 19.05 & 62 & 98.41 & $78.6192 \#$ & 63.00 \\
Total & 63 & 63.00 & 63 & & \\
\hline
\end{tabular}

${ }^{*} \mathrm{p}<0.05$, \# applied chi-square with yates correction

\section{DISCUSSION}

Comprehensive knowledge of root and canal morphology is fundamental for successful root canal treatment. The complexity of the root canal system determines the difficulty of root canal treatment. The omission of root canals may leave microorganisms and infectious pulp tissue untouched, which could cause posttreatment disease. ${ }^{8}$ It has been suggested that although various techniques have been used to evaluate root canal morphology, the most detailed information is obtained by demineralization and staining, which is superior for three-dimensional assessment of internal morphology of the root canal system..$^{9,10}$

In Saudi Arabia, the occurrence of three-rooted mandibular first molars has been reported to range from $2.3 \%$ by Younes et al. ${ }^{11}$ (1990) to $22.7 \%$ in Japan by de Souza-Freitas et al. (1971). ${ }^{12}$ In a study done in Saudi Arabia among a sample of 251 root canals treated permanent mandibular first molars the results showed that $5.97 \%$ of treated cases had a three-rooted mandibular first molar. ${ }^{5}$ In the present study, 6 mandibular first molars were found to be three-rooted.(Fig 1-6) The results of this study show a higher frequency of three-rooted first molar than reported by Younes et al. ${ }^{11}$ and was in comparison to that reported by Al-Nazhan. ${ }^{5}$ In Iran prevalence of three roots in mandibular first permanent molars was found to be $1.44 \%$ which was very less when compared to present study. ${ }^{13}$ Zhang et al, reported $21.8 \%$ prevalence of three roots with four root canals in mandibular first molars, a Chinese sub population. ${ }^{14}$ Chandra et al., observed a prevalence of 3rooted mandibular first molars in $18.6 \%$ of the patients examined and $13.3 \%$ of the teeth examined. There was no statistically significant difference between genders or side of occurrence. The bilateral incidence of a symmetric distribution was $43.01 \%{ }^{15}$ Gulabivala et al., reported the prevalence of three-rooted mandibular first molars to be $13 \%$ in a Thai population. ${ }^{16}$

Regarding the occurrence of the fourth canal, this study revealed that $63.0 \%$ had four root canals, which slightly more than reported by Al-Nazhan. ${ }^{5}$ Whereas in a study carried out in Bangladesh by Khan et al., 45.92\% teeth were found with four canals, which was less than that of the present study. ${ }^{17}$ The race and ethnicity differences among the populations may be the important factors observed in root canal configuration between the current study and the other studies.

\section{CONCLUSIONS}

The observations of the present study are very significant in assisting the dental practitioners to provide adequate knowledge about the root canal morphology of the majority of population residing in Kingdom of Saudi Arabia and about the possible morphological variations. Thus, the dental practitioners will develop necessary skills to locate, clean and shape the entire root canal system and will lead to higher level of success in root canal treatment

\section{LIMITATIONS}

Less sample size

\section{FUTURE PERSPECTIVES}

Further researches about this topic should be carried out in a larger and more varied population utilizing Cone Beam Computed Tomography.

\section{SOURCE OF SUPPORT}

This study was funded by the Al Jouf University, Kingdom of Saudi Arabia. Research Project No. (283/35).

\section{REFERENCES}

1. Adanir N. An unusual maxillary first molar with four roots and six canals - A case report. Aust Dent J. 2007; 52:333-335.

2. European Society of Endodontology. Quality guidelines for endodontic treatment: consensus report of the European Society of Endodontology. Int Endod J. 2006; 39:921-30.

3. Munavalli A, Kambale S, Ramesh S, Ajgaonkar N. Mandibular first molar with single root and single root canal. J Conserv Dent. 2015 Jul-Aug; 18(4): 346-348.

4. Kottoor J, Sudha R, Velmurugan N. Middle distal canal of the mandibular first molar: A case report and literature review. Int Endod J. 2010;43:714-22.

5. Al-Nazhan S. Incidence of four canals in root-canal-treated mandibular first molars in a Saudi Arabian sub-population. Int Endod J 1999;32:49-52.

6. Harty FJ. Endodontics in Clinical Practice, John Wright and Sons, 2nd ed. Bristol. 1990; 259-65.

7. Chourasia HR, Meshram GK, Warhadpande M, Dakshindas D. Root Canal Morphology of Mandibular First Permanent Molars in an Indian Population. Int J Dent. 2012; 2012: 745152. 
8. Narayanan LL, Vaishnavi C. Endodontic microbiology. J Conserv Dent. 2010 Oct-Dec; 13(4): 233-239.

9. Vertucci FJ. Root canal anatomy of the human permanent teeth. Oral Surg Oral Med Oral Pathol 1984;58(5):589-99.

10. Omer OE, Al Shalabi RM, Jennings M, Glennon J, Claffey NM. A comparison between clearing and radiographic techniques in the study of the root-canal anatomy of maxillary first and second molars. Int Endod J 2004;37(5):291-6.

11. Younes SA, al-Shammery AR, el-Angbawi MF. Three rooted permanent mandibular first molars of Asian and black groups in the Middle East. Oral Surg Oral Med Oral Pathol 1990;69(1):1025.

12. de Souza-Freitas JA, Lopes ES, Casati-Alvares L. Anatomic variations of lower first permanent molar roots in two ethnic groups. Oral Surg Oral Med Oral Pathol 1971;31(2):274-8.

13. Shahi S, Yavari HR, Rahimi S, Torkamani R. Root Canal Morphology of Human Mandibular First Permanent Molars in an Iranian Population. J Dent Res Dent Clin Dent Prospects. 2008 Winter; 2(1): 20-23.

14. Xin Zhang, Shijiang Xiong, Yue Ma, Ting Han, Xinyu Chen, Fang Wan, et al. A Cone-Beam Computed Tomographic Study on Mandibular First Molars in a Chinese Subpopulation. PLOS ONE. 2015;10(8):e0134919.

15. Chandra SS, Chandra S, Shankar P, Indira R.Prevalence of radix entomolaris in mandibular permanent first molars: a study in a South Indian population. Oral Surg Oral Med Oral Pathol Oral Radiol Endod. 2011 Sep;112(3):e77-82.

16. Gulabivala K, Opassanon A, Ng Y-L, Alavi A. Root and canal morphology of Thai mandibular molars. Int Endod J. 2002;35:5662.

17. A Khan, R Ahmed, SS Chowdhury, SMA Qauder. Incidence of four canals in root-canal-treated mandibular first molars in Bangladeshi population. Updat Dent. Coll .j 2014;4(2):04-08.

\section{Conflict of Interest: None Declared.}

Copyright: (c) the author(s) and publisher. IJMRP is an official publication of Ibn Sina Academy of Medieval Medicine \& Sciences, registered in 2001 under Indian Trusts Act, 1882.

This is an open access article distributed under the terms of the Creative Commons Attribution Non-commercial License, which permits unrestricted non-commercial use, distribution, and reproduction in any medium, provided the original work is properly cited.

Cite this article as: Azhar Iqbal. The Evaluation of Mandibular First Permanent Molars to Determine the Incidence of Three Roots and Four Canals in Aljouf Region of Saudi Arabia. Int J Med Res Prof. 2016; 2(5):216-21. 